\title{
A arte de esquecer
}

\author{
IVÁN IZQUIERDO, \\ LIA R. M. BEVILAQUA e MARTÍN CAMMAROTA
}

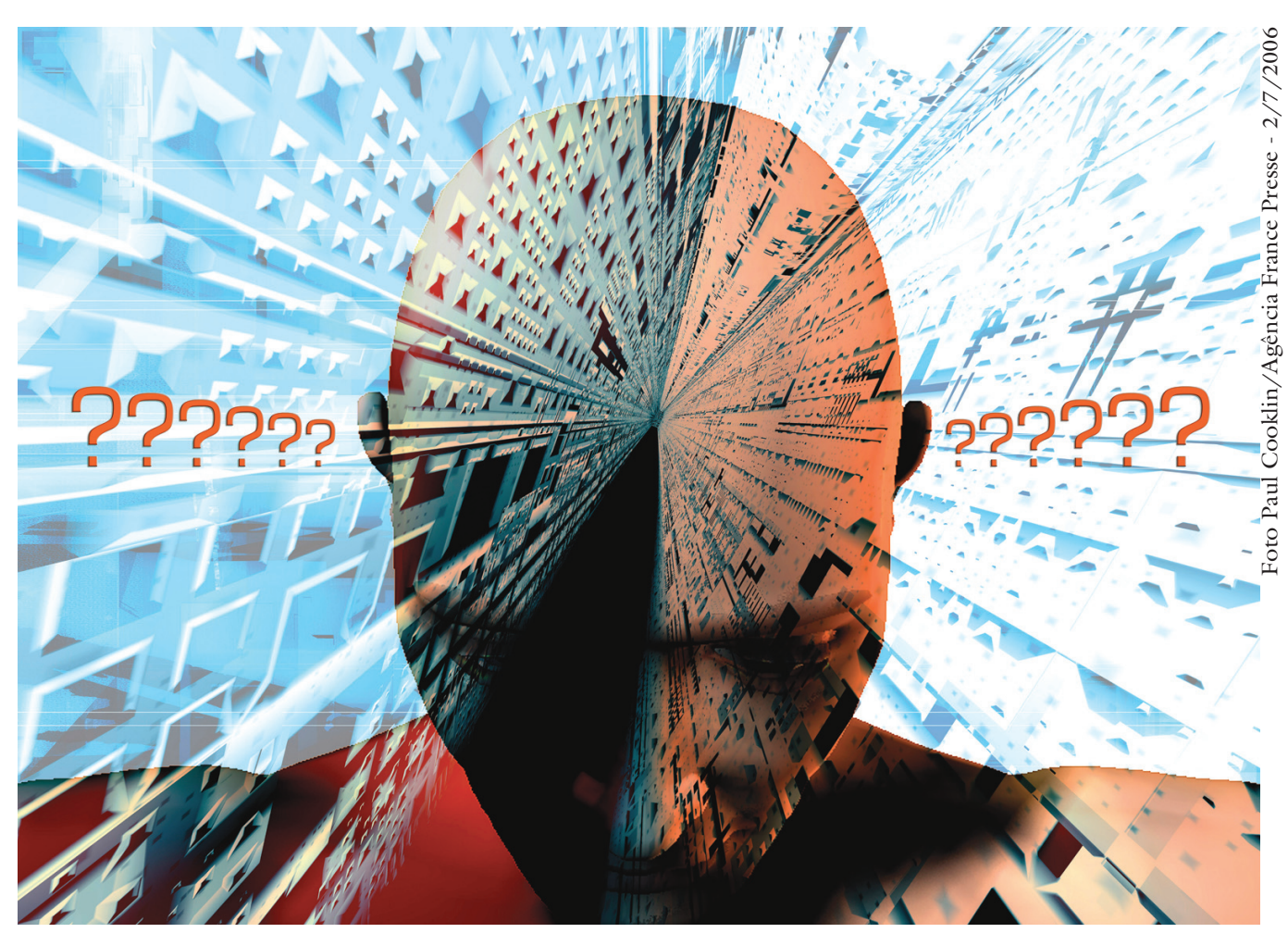

$\mathrm{T}$

ALVEZ O MAIOR pesquisador na área da Memória nos últimos 50 ou 60 anos, James McGaugh, da Universidade de Califórnia em Irvine, num livro publicado em 1971, apontou que "talvez o aspecto mais notável da memória é o esquecimento" (Harlow et al., 1971).

De fato, esquecemos a imensa maioria das informações que adquirimos. Todos reconhecem que a infância é o período mais importante de nossa vida, porém, se nos convidarem a relatá-la, nenhum de nós levaria mais do que umas poucas horas. $\mathrm{O}$ médico que mais sabe sobre Medicina poderá expor tudo o que sabe também, no máximo, em poucas horas. A maioria de nós lembra com detalhes o que estava fazendo, onde e com quem, no momento em que morreu Ayrton Senna; ninguém se lembra do que aconteceu 24 horas antes ou depois. A morte do Senna é uma memória altamente emocional, que recordaremos sempre porque foi gravada de maneira indelével (ver comentário no final deste artigo); as memórias do dia anterior e do dia posterior correspondem a memórias inexpressivas, que logo esquecemos para sempre. 
Há várias razões e mecanismos para isso. Para começar, os mecanismos da memória se saturam (Izquierdo, 2002). Para continuar, Jorge Luis Borges, num conto chamado "Funes o Memorioso", demonstrou, pelo absurdo, que lembrar tudo é impossível. O personagem, Funes, pode lembrar até o último detalhe um dia inteiro de sua vida, mas, para fazê-lo, requer outro dia inteiro de sua vida, o que é impossível (Borges, 1943).

De fato, é necessário esquecer, ou pelo menos manter longe da evocação muitas memórias. Há muitas que nos perturbam: aquelas de medos, humilhações, maus momentos. Há outras que nos prejudicam (fobias) ou nos perseguem (estresse pós-traumático). Em razão do problema da saturação, existem memórias que nos impedem de adquirir outras novas ou adquirir outras antigas, mais importantes (por exemplo, como fugir em uma situação de medo).

Borges, em seu conto, aponta que Funes era "incapaz de esquecer para poder pensar, (pois) para pensar é necessário esquecer (detalhes) para poder fazer generalizações".

\section{Formas de esquecimento}

Há várias. A mais estudada é a extinção, à qual dedicaremos algumas linhas a seguir. Outra, popularizada por Freud, é a repressão, talvez vinculada com a anterior. Existem memórias que não ultrapassam poucos segundos, e ficam na memória de trabalho. Outras não ultrapassam a memória de curta duração (e não ficam na memória de longa duração). Outras memórias duram poucos dias e depois desaparecem. Por último, há o esquecimento real: memórias que desaparecem por falta de uso, com atrofia sináptica.

\section{Extinção}

Descoberta por Pavlov há mais de um século, a extinção se deve à desvinculação de um estímulo condicionado do estímulo incondicionado com o qual tinha se associado e gerado uma resposta aprendida; o estímulo passa a se vincular com a ausência desse último estímulo. Por exemplo, se associamos uma campainha (estímulo condicionado) com um choque elétrico (estímulo incondicionado) e com isso se gera uma resposta de flexão, e passamos a apresentar à campainha isolada, sem o choque, essa aos poucos irá se associando com a falta de choque e a resposta de flexão será suprimida. A campainha deixa de sinalizar um choque; passa a sinalizar que não virá mais um choque. Se vamos todos os dias a um guichê onde recebemos dinheiro, e a partir de certo dia lá não nos dão mais dinheiro, associaremos o guichê com a falta de dinheiro.

Isso tem um tremendo valor adaptativo, porque nos impede de insistir na realização de comportamentos (ou em manter pensamentos) que já não se ligam mais com a realidade. A partir da última série da escola, não precisamos mais nos lembrar daquele professor de aspecto feroz...

A extinção foi muito estudada em nossos laboratórios. Depende da ativação de receptores glutamatérgicos NMDA (N-metil-D-aspártico), proteína 
cinase dependente de AMPc (PKA), proteínas cinases reguladas extracelularmente (ERKs), proteína cinase dependente de cálcio e calmodulina (CaMKII), expressão gênica e síntese protéica em uma ou mais das seguintes estruturas: hipocampo, amígdala basolateral, córtex entorrinal e área pré-frontal ventromedial (Vianna et al., 2001, 2004; Milad \& Quirk, 2002; Bevilaqua et al., 2006). A relação com uma ou outra estrutura depende da tarefa utilizada em animais (Myers \& Davis, 2002); o córtex pré-frontal ventromedial parece ser necessário para todas, e nele a extinção se correlaciona com atividade elétrica específica e há necessidade de síntese protéica. A participação de várias dessas estruturas na extinção do medo aprendido foi confirmada por ressonância magnética funcional em humanos (Phelps et al., 2004).

Utiliza-se desde Freud (1959) a extinção na terapia do medo aprendido. Ele e seu discípulo S. Ferenczi a aplicaram em um caso de fobia, dando-lhe o nome de "habituação" (Freud não tinha simpatia alguma por Pavlov, para quem a habituação era outra coisa (Vianna et al., 2000)). O sucesso foi imediato e, a partir deles, a extinção foi largamente empregada no tratamento do medo aprendido (Rothbaum \& Schwartz, 2002; Cammarota et al., 2003). Nos últimos anos, tem sido empregada como tratamento de escolha na terapia do TEPT (transtorno de estresse pós-traumático); alguns autores norte-americanos preferem chamá-la de exposure therapy (Beckett, 2002; Rothbaum \& Schwartz, 2002). Na extinção, de fato, o terapeuta faz uma (sobre)exposição do paciente a fotografias ou a outras circunstâncias pertinentes ao trauma inicial, salientando a ausência de conseqüências perigosas ou assustadoras nessa exposição. Em trabalhos recentes, nosso grupo estudou de maneira paramétrica como pode ser feita essa sobreexposição do antigo estímulo condicionado sem conseqüências temíveis no rato; foi obtida uma extinção completa que requereu nova expressão gênica e síntese protéica no hipocampo para restabelecer a resposta original (Cammarota et al., 2003).

\section{Repressão}

Um dos postulados mais heurísticos de Freud foi o da repressão de memórias. Essa pode ser voluntária ou inconsciente. Na primeira, propomo-nos a cancelar a evocação de memórias que nos causam desagrado, mal-estar ou prejuízo: "Não quero me lembrar mais da cara daquele sujeito (ou daquele lugar, ou daquele incidente)". Na segunda, o cérebro faz isso por conta própria, para o qual evidentemente tem uma tendência autoprotetora. Há muitas evidências de que ambas as formas de repressão representam, essencialmente, a mesma coisa. Se o cérebro reprime determinada(s) memória(s), deverá ser em razão de um estímulo originado em algum lugar, seja esse voluntário ou não. Esse estímulo deve provir da própria memória, por definição.

Anderson et al. (2004) estudaram a atividade de várias áreas cerebrais na repressão voluntária, tomada explicitamente como exemplo das duas formas de repressão. Verificaram que no momento da repressão ativa-se o córtex pré-fron- 


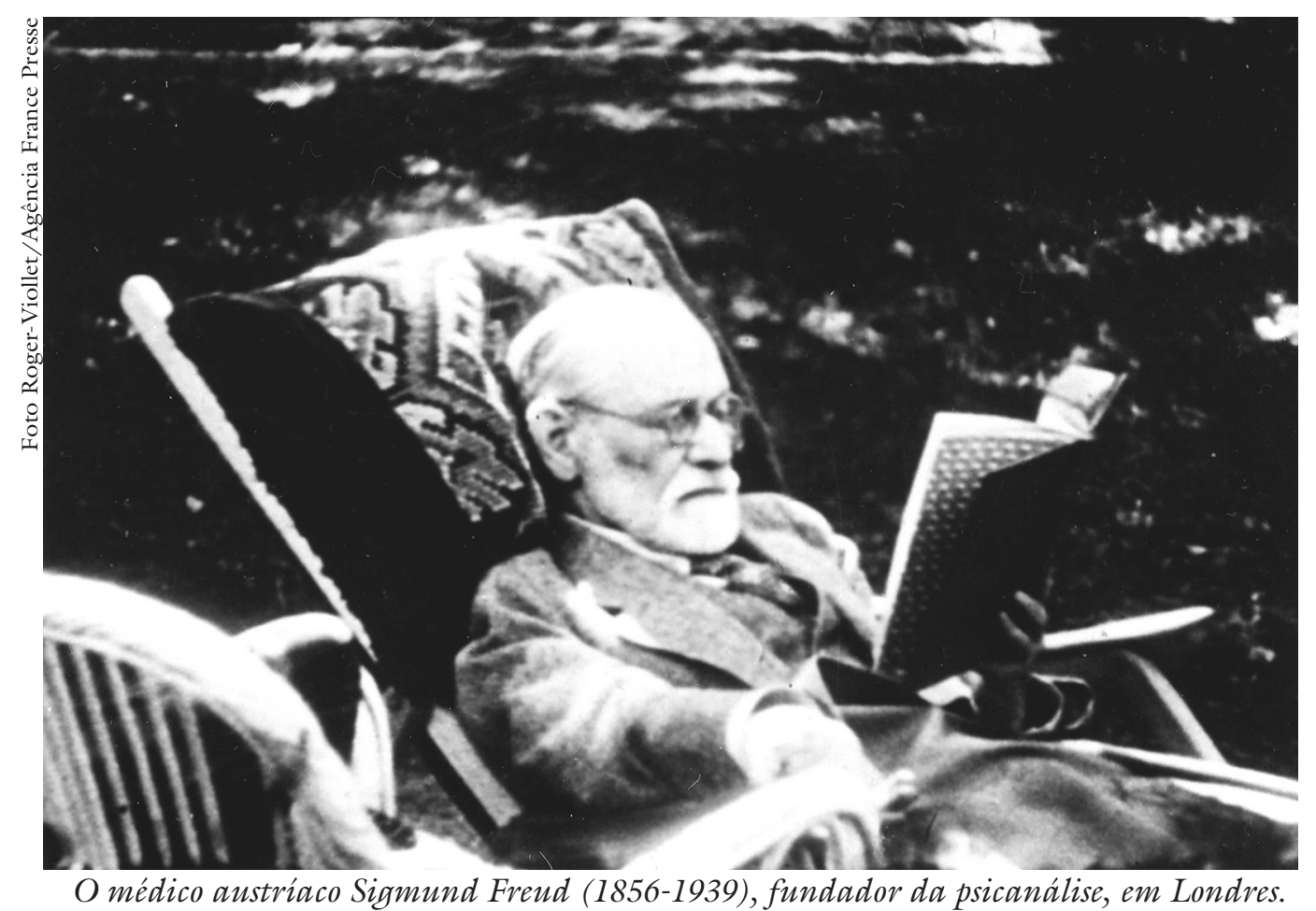

tal ântero-lateral, concomitantemente com uma diminuição da atividade do hipocampo, área vinculada fortemente com a evocação.

Ou seja, uma região diferente do córtex pré-frontal vincula-se com a repressão. Estudos recentes de nosso laboratório apontam, porém, para uma relação estreita entre ambas as regiões pré-frontais, em relação à construção de memórias de longa duração a partir da informação que elas processam durante a prática da memória de trabalho.

\section{A extinção e a repressão não equivalem ao esquecimento real}

Tanto as memórias extinguidas como as reprimidas podem voltar à tona, quer espontaneamente quer como conseqüência de estímulos específicos (Rescorla, 2001; Izquierdo, 2002; Cammarota et al., 2003). Não correspondem, portanto, ao conceito de esquecimento real, pelo qual as memórias efetivamente se perdem. Os mecanismos da extinção e da repressão são ativos e envolvem a inibição específica de uma ou mais memórias por intervenção de mecanismos nervosos determinados (córtex pré-frontal ventromedial, hipocampo, amígdala, córtex entorrinal em um caso; córtex pré-frontal ântero-lateral, hipocampo em outro). Na extinção, os mecanismos moleculares que a sustentam são em boa parte conhecidos (ver acima).

\section{A persistência das memórias por períodos curtos também não corresponde ao esquecimento real}

Há formas de memória que duram poucos segundos ou minutos (memória de trabalho) ou poucas horas (memória de curta duração). 
A memória de trabalho retém as informações na medida em que essas vão aparecendo, essencialmente on-line ou por um curto tempo a seguir. Um bom exemplo é o da terceira palavra da frase anterior; todos a retiveram só o tempo suficiente para entender essa frase, e talvez a seguinte. A essa altura, já a perderam; se não voltarem atrás para relê-la, não a recordarão.

A memória de curta duração é um processo mnemônico desenvolvido no hipocampo e no córtex entorrinal, utilizando mecanismos em boa parte próprios e independentes das memórias de longa duração que ao mesmo tempo estão sendo geradas (Izquierdo et al., 1998). Dura no máximo seis horas e serve ao propósito de um albergue provisório para a informação que depois poderá ou não ser armazenada como memória mais estável ou permanente; corresponde ao que William James (1890) denominava "memória primária”.

A maior parte dos componentes da memória de trabalho desaparece em segundos; os da memória de curta duração não persistem além de umas poucas horas, a menos que se tenha conseguido construir uma memória de longa duração ao mesmo tempo (Izquierdo et al., 1998; Izquierdo, 2002).

A não-persistência dessas memórias mais breves decorre de seu papel fisiológico e não implica esquecimento algum. Um jogador de futebol se lembrará da cara daquele jogador do time oposto que o perseguia durante o jogo; depois, especialmente se seu time ganhou, o esquecerá. Se for de algum adversário longínquo (coreano, suíço), esquecerá para sempre.

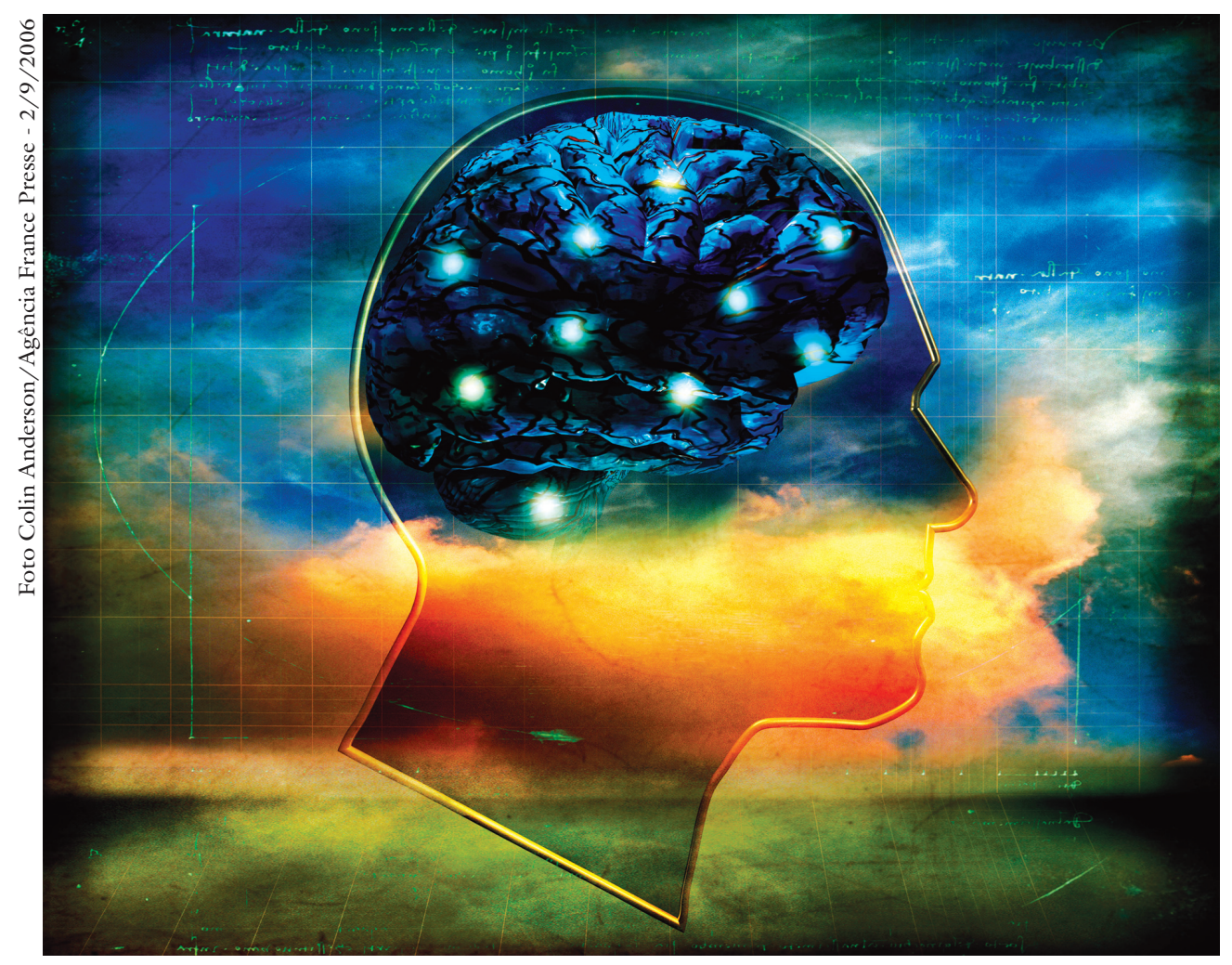




\section{$\mathrm{E}$ as memórias que duram poucos dias?}

Todos nós que alguma vez estudamos só para uma prova (o vestibular, por exemplo) sabemos que há memórias que não persistem além da prova. Um ou dois dias depois as esquecemos para sempre.

Numerosos trabalhos demonstram que na construção de uma memória de longa duração são necessárias a expressão gênica e a síntese protéica nas primeiras três a seis horas, no hipocampo ou em outras regiões vinculadas a esse processo (cf. Cammarota et al., 2003; Izquierdo et al., 2006). Estudos recentes feitos pelo grupo de J. H. Medina em Buenos Aires, em colaboração com o nosso, sugerem que há um segundo processo que envolve síntese protéica no hipocampo doze horas depois da aquisição, pelo qual as memórias persistem para além das 48 horas depois de apreendidas. Esse processo pode se denominar "manutenção" e requer também pelo menos um fator neurotrófico (o BDNF) no hipocampo, ao mesmo tempo que requer síntese protéica, isto é, doze horas depois de ter adquirido uma memória.

\section{O esquecimento real}

Como vimos no início, porém, além das diversas maneiras que existem de inibir a evocação e/ou de "escantear" memórias, há muitíssimas dessas que se perdem inexoravelmente e de forma irreversível. Ninguém se lembra do que fez na tarde de 4 de agosto de 1996 ou na hora seguinte após ter visto determinado filme. A menos que essa data ou essa hora tenha coincidido com algum evento emocionalmente forte. As memórias com conteúdo emocional forte são gravadas com participação das vias nervosas que regulam as emoções, que agem estimulando vias enzimáticas hoje bem determinadas no hipocampo e outras regiões a ele ligadas ( a via da PKA). Essas vias estimulam indiretamente a formação de novas sinapses como sustentáculo dessas memórias e essas costumam, assim, persistir muitos meses ou anos (Izquierdo et al., 2006).

Fora dessas memórias, as demais, no entanto, duram pouco tempo; e se não repetidas (se não revividas), desaparecem por falta de uso. A falta de uso causa atrofia das sinapses (Eccles, 1957), e isso explica desde há pelo menos cinqüenta anos por que as memórias nunca lembradas, assim como os movimentos não mais feitos ou os pensamentos nunca mais revisitados, desaparecem.

A memória é a função cerebral que mais se encaixa com o dito de que "a função faz o órgão". Se praticada intensamente, a memória como função não esmorece; se não recordada, dissolve-se no esquecimento. Muitos trabalhos recentes indicam como isso é possível (Nader, 2003; Rossato et al., 2006).

A melhor forma de manter viva a memória, em geral, é por meio da leitura (Izquierdo, 2002). A melhor forma de manter viva cada memória em particular é recordando-a. Como isso nem sempre é possível, e certamente não desejável, devemos nos aprimorar na prática da arte de esquecer, tão cantada pelos poetas, desde Ovídio até Borges. 
Referências bibliográficas

ANDERSON, M. C. et al. Neural systems underlying the suppression of unwanted memories. Science, v.9, 303, p. 232-5, 2004

BECKETT, W. S. Post-traumatic stress disorder. New Eng. J. Med., v.346, p.1495-8, 2002.

BEVILAQUA, L. R. et al. The entorhinal cortex plays a role in extinction. Neurobiol. Learn. Mem., v.85, p.192-7, 2006.

BORGES, J. L. Ficciones. Buenos Aires: Emecé, 1943.

CAMMAROTA, M. et al. Inhibition of mRNA and protein synthesis in the CAl region of the dorsal hippocampus blocks reinstallment of a conditioned fear response. J. Neurosci., v.23, p.737-41, 2003.

ECCLES, J. C. The Physiology of Synapses. Berlin: Springer, 1957.

FREUD, S. The Standard Edition of the Complete Works of S. Freud. London: Hogarth Press, 1959. v.3, p.74.

HarloW, H.; McGaugh, J. L.; THOMPSON, R. F. Psychology. San Francisco: Albion, 1971.

IZQUIERDO, I. Memória. Porto Alegre: ArtMed, 2002.

IZQUIERDO, I. et al. Mechanisms for memory types differ. Nature, v.393, p.635-6, 1998.

Different molecular cascades in different sites of the brain control memory consolidation. Trends Neurosci, v.29, p.496-505, 2006.

JAMES, W. The Principles of Psychology. New York: Holt, 1890.

MILAD, M. R.; QUIRK, G. J. Neurons in medial prefrontal cortex signal memory for fear extinction. Nature, v.26, p.70-4, 2002.

MYERS, K. M.; DAVIS, M. Behavioral and neural analysis of extinction. Neuron, v.36, p.567-84, 2002.

NADER, K. Memory traces unbound. Trends Neurosii., v.26, p.65-70, 2003.

PAVLOV, I. P. Conditioned Reflexes. New York: Dover, 1959.

PHELPS, E. A. et al. Extinction learning in humans: Role of the amygdala and vmPFC. Neuron, v.43, p.897-905, 2004.

RESCORLA, R. A. Retraining of extinguished Pavlovian stimuli. J. Exp. Psychol. Animal Behav. Proc., v.27, p.115-24, 2001.

ROSSATO, J. I. et al. Retrieval induces hippocampus-dependent reconsolidation of spatial memory. Learn. Mem., n.13, 2006.

ROTHBAUM, B. O.; SCHWARTZ, A. C. Exposure therapy for posttraumatic stress disorder. Am. J. Psychother., v.56, p.59-75, 2002.

VIANNA, M. R. et al. Role of hippocampal signaling pathways in long-term memory formation of a non-associative learning task in rats. Learn. Mem., v.7, p.333-40, 2000.

Retrieval of memory for fear-motivated training initiates extinction requiring protein synthesis in rat hippocampus. Proc. Nat. Acad. Sci., v.98, p.12251-4, 2001. 
VIANNA, M. R. et al. Role of the hippocampus and amygdala in the extinction of fearmotivated learning. Curr. Neurovasc. Res., v.1, p.55-60, 2004.

RESUMO - NOS ÚLTIMOS vinte anos vimos presenciando um notável avanço no que diz respeito ao conhecimento acerca dos mecanismos moleculares envolvidos na aquisição, consolidação e expressão de memórias. Porém, e apesar de que resulte óbvio que a nossa capacidade de formar novas memórias está intimamente ligada a sua perda, muito pouco se sabe a respeito do esquecimento. Quais as causas do esquecimento? Como esquecemos? Existe um processo ativo de esquecimento ou esse fenômeno é simplesmente decorrente da interferência de outras memórias ou da passagem do tempo? Neste artigo, comentamos brevemente este e outros temas relacionados com a persistência da memória, em particular, analisamos a influência que a utilização do traço mnemônico tem na sua perdurabilidade.

PALAVRAS-CHAVE: Memória, Esquecimento, Extinção, Repressão.

ABSTRACT - IN THE LAST twenty years we have witnessed an extraordinary progress in our knowledge about the molecular processes involved in memory acquisition, consolidation and retrieval. However and despite the fact that memory formation is indissolubly intermingled with memory forgetting, we know very little about this phenomenon. What are the causes of forgetting? How do we forget? Is there an active forgetting process or this phenomenon is simply due to interference by other memories or to decay due to the passage of time? In this review, we comment briefly on this subject and others related to memory persistence. In particular, we analyze whether expression of the mnemonic trace has any effect on its perdurability.

KEYWORDS: Memory, Forgetting, Extinction, Repression.

Iván Izquierdo (izquier@terra.com.br),Lia R.M. Bevilaqua (liabevilaqua@terra.com. br) e Martín Cammarota (mcammaro@terra.com.br) são pesquisadores do Centro de Memória do Instituto de Pesquisas Biomédicas (IPB) da Pontifícia Universidade Católica do Rio Grande do Sul (PUC-RS).

Arte de esquecer foi tema da Conferência de Iván Izquierdo promovida pelo IEA-USP no dia 28 de junho de 2006.

Recebido em 27.6.2006 e aceito em 5.7.2006. 